\title{
Characteristics of Chinese Composers' Art Songs from the Twentieth Century to the Early Twenty-first Century
}

\author{
Yi Liu \\ Kharkiv National V.N.Karazin University \\ Kharkov, Ukraine
}

\begin{abstract}
This article is an overview of the characteristics of Chinese art songs from the Twentieth Century to the early Twenty-first Century. The article has analyzed the role of art songs in the national music art and culture development and demonstrated the development regularity of Chinese art songs from the perspective of national particularity, expansion of topics, source of poetry and rich writing skills of composers.
\end{abstract}

Keywords-Chinese art songs; song creation; creative characteristics

\section{INTRODUCTION}

Chinese music culture has a long tradition of singing, which determines the particularity of vocal music genres in Chinese professional composers. Vocal music genre is often the center of Chinese composers in art exploration. From ancient times to now, the music genre of art songs has always been one of the main objects in art exploration. As we all know, music theory is closely related to practice. Therefore, the researchers are interested in the many genres of Chinese vocal music in the development, which is also reasonable and obvious.

It is necessary to study the difficult course of the development of Chinese national music comprehensively. However, it can also be considered on the basis of the research of different subjects and on the basis of the historical inheritance and mutual relationship of these subjects. The most important meaning of art song creation is to compile the whole national culture history, among which national character occupies the leading position. In the Twentieth Century, many Chinese professional composers started their careers with songs and lyric songs.

The creation of He Lvting was centered on the creation of Nie Er, Xian Xinghai, Liu Xuean and others. For the latter generation of composers, these music creations of previous composers still have their meaning. Over ten years of modern works and precious works of art have clearly displayed cyclical manifestations, and have proved the reality and prospect of this cycle.

The main purpose of this article is to show the important features of Chinese art song creation from the Twentieth Century to the early Twenty-first Century, and the influence on the creation of national music and the traditional style of eastern and western music. We will discuss one of the most important issues in this field: the relationship between music and language, which determines the extent of the influence of accents on melodic characteristics in different dialects of Chinese, and transforms the composition and drama creation of vocal music into a specific thinking image, as well as complex structure, subject matter and the thinking element of national music in figure of speech.

\section{The Stage Division OF Chinese ARt SONGWRITING} HISTORY FROM THE 20TH CENTURY TO EARLY 21ST CENTURY

Twentieth Century was also the era of China's achievement in western music thinking and composing techniques. In the history of Chinese music from the Twentieth Century to the beginning of Twenty-first Century, it can be divided into several periods. From 1920 to 1930, the first group of ethnic composers began their composition. The founder of Chinese music education was Xiao Youmei (1884-1940). He became the first professional composer in China. He has ever taught music education abroad. He also began to use and develop western composing techniques in his own composition.

The first batch of Chinese composers has ever taught music education in the United States, Germany, France, Belgium and Japan. They were Zhao Yuanren, Qing Zhu, Huang Zi, Xi Xinghai, Ma Sicong and others. For Chinese composers who have received basic education in European music system, the greatest significance is to master the basic knowledge of national art.

The founders of art songs were Qing Zhu, Zhao Yuanren, He Lvting, Huang Zi, Nie Er and Liu Xuean. Their works have laid the foundation for the nationalism of music melody in the development of folk music, and have been adopted in the creation of western piano music. From 1940 to 1950, Ding Shande, Li Yinghai, Ma Ke, Huang Hubei, Du Jiang, Wang Beiyuan and Wang Lishan began their composing career. During this period, they wrote a lot of vocal works and became classics of national art.

During the Cultural Revolution (from 1966 to 1977), it was a difficult period for Chinese music art. They have accomplished many revolutionary songs with political 
characteristics in the creation. The artistic value of these songs cannot be estimated until now.

From $70 \mathrm{~s}$ to $90 \mathrm{~s}$, music creation has a higher level of composing professionalism, such as works of composer Tang $\mathrm{Du}$, Guo Wenying and $\mathrm{Chu}$ Xiaosong. They have unique creative thinking, unique style of their own words, and the personal form of interaction between our tradition and the Western tradition. And on these bases, they have expanded and updated the techniques of composing music.

In the early Twentieth Century, the melody creation of vocal music in Chinese art song genres was regarded as a unique phenomenon and developed in the national music and the traditional music of the East and the West. The creation of art songs is to find diverse patterns of expression, and to make use of the observed folklore to influence the development of vocal music, including the influence of opera. Ethnic composers were changing their original ideas.

In the creation of Zhu Liangzhen, Ding Shande, Wang Lishan and Shi Guangnan, a small amount of literature was presented. It wrote that: try to understand the inherent law of the national art, to select a unique tone from the folk tune, and to combine with the themes of the works to find its own position and the style, like the composer Zhu Jianer and Rao Xiaosheng and foreign composer Chen Yi. They also expressed their aspirations on the stage of other countries and won international awards.

The genre of art songs is supported by the best folk music tradition. The types of folk songs include the festival music in China, as well as the Oriental recitation tradition and poetry and humming. The rich national tradition has ensured the professional artistic achievements of Chinese vocal music creation in the future. The formation of Chinese vocal music works is based on the European music theory and a process of innovation: lyric songs, long poems, ballads, music poems and other vocal works. They achieve their national characteristics by decorating melodies, discontinuous tunes and developing variability. At the same time, it is also a time to grasp and develop the expressive power of European Romanticism and Impressionism.

In recent decades, understanding each work is like understanding all kinds of social and life phenomena. The composers of art songs, taking the social reality of the time as background, combined the characteristics of national music with the characteristics of the eastern and western art, and used modern western writing techniques to eventually form a new style of their own. The work of Chinese art songs is growing and maturing, and the integration with symphonic and script elements is further strengthened.

Today, the most outstanding and most representative art songs are from Zhu Jianer, Shi Guangnan, Zhu Xiaoyun, Xue Jiangchang and Chen Yi. They could fully display the lyric ability of music in the creation of melody, and provide valuable experience in writing themes, skills and lyric ways for Chinese contemporary composer's art songs composition. They have inherited the historical and cultural traditions of the Chinese nation. They often told a story or describe a character in their own works. The most significant part of vocal music is the lyric works of patriotic subjects, which was first formed in the traditional music of the West and Russia. Usually, with the background of the great times, the traditional melody style, the local language and the psychological activities of the characters are combined to express the friendship sentiment of them to the nation.

The main style characteristic of Chinese composers is good at depicting and describing rich and meticulous emotions, and driving the change of the tone melody by emotional changes. The style of Chinese art songs is characterized by the good use of polyphonic techniques to lead the development of the melody. This makes the work form more and more personalized and rich in the process of creation, and the music language is more complex and diverse.

\section{NEW FEATURES OF CONTEMPORARY ART SONGWRITING}

In the contemporary era, vocal lyric works are the most subjective in all forms and types of musical art. It expands the boundaries of Chinese music creation, supplemented by social philosophy and secular views. The topics of vocal music include philosophy, lyric image and natural world in daily life. In the main position are lyric works. On this basis, several types of art songs have been formed: psychological lyric type, philosophical lyric type, dramatic lyric type, and so on.

In recent decades, with the growing awareness of the surrounding world, the lyric characteristics of many works are based on the deepening of psychology and expanded in the field of poetry. In connection with other genres of music and art, the reforming characteristics are highlighted. The creation of Chinese composers has been developing in the main trend of contemporary world music art.

The main themes, plots and images have appeared on the land of China, and the composer's creative personality has also been shown. Composer Zhu Jianer's vocal creation was a special phenomenon in Chinese music art. The scope of his vocal works was wide, including philosophical, romantic and natural lyric works. The tune of his works is extremely melodious, and the obvious emotional nature of the poem is closely related to the composer's personal experience. The images, emotions and forms of his works coincide with his spiritual needs. The melody style of Zhu Jianer's works is the integration of melodic beginning, romantic narrative and recitation suitable for the folk narrative music genre. In the past 20 years, his works have deep feelings and flexible style. The relationship with folk music has become more subtle.

Zhu Liangzhen's vocal works fully show the theme of love. Here, the author's creative goals determine the special way of describing lyricism and expressing emotions. For him, the archetype of poetry has become an important factor in choosing the way of music. The language style of his works has unique characteristics in different periods, combining folk music materials with Chinese and Western writing techniques.

Shi Guangnan's vocal works are mainly about the theme of praising the motherland. The lyric beginning of the beautiful aria is the foundation of the recital melody. The development of tone is to show the changes of mind and mood, which is 
achieved through various ways of development. And on the basis of the national tradition, the author maintained and applied the style characteristics of Chinese regional culture and folk music genres: lyric mountain songs (taking mountains and prairies as lyric carriers), and the pronunciation methods of Chinese musical instruments, huqin and pipa.

The style of modern Chinese composers came into being on the basis of many musical phenomena in the Twentieth Century. It combines expressive force with negative inaction, philosophy with meticulous lyric to reflect sharp social problems, the voice of the times and the aspirations of the people. The distinctive character of the times is one of the important characteristics in composition at that time.

The music composition of Chinese composer who has immigrated to other countries is also an interesting phenomenon. Nowadays, Chinese Chen $\mathrm{Yi}$ and Sheng Zongliang are regarded as modern outstanding musicians. In recent years, more and more Chinese young composers, such as Huang Ruo, Lei Liang and Hao Ping, have gained popularity. They are still influenced by western music ideas. New ideas, new methods, and new experiments are full of their imagination and creative thinking. All of them are looking for their own unique style and expanding their field of composition. Nevertheless, the source of their inspirations is mainly rooted in their subconscious awareness of Chinese national culture. The theme of their music works is about life, death, and love and art creation. Their performances have characteristics of lyric drama creation and psychological suggestion.

In the genre of art songs, Composers Chen Yi, Sheng Zongliang and Zhou Long turn to thematic works, creating a series of poetry of different ages. Poets in the Tang and Song Dynasties and the poetry in the Book of Songs aroused great interest. The lyric songs still retain the rhyme and rhythm of poetry. The composers flexibly apply the emphasis of thoughts, repeat the fragments of poetry, and divide the sentences in the paragraph.

\section{CONCLUSION}

The study of Chinese composers' art songs shows that the development of the theme and the structure of the Western multi-part art can be successfully combined with the Chinese national music elements which are dominated by lyric solo, improvisational performance and obvious process. The influence of the Eastern tradition and the Western tradition is manifested in the combination of the traditional national genres and some European genres, such as poems, monologues, narrative ballads, and vocal music, the combination of the development of the lines with the narrative chorus and chorus structure, the combination of the continuity and structure of musical materials and the combination of major and minor system and the national style.

Nowadays, in the field of art song creation, Chinese composers actively seek new expressive methods and forms, which have influenced the contemporary national drama, instrumental art and chorus art. The great significance of the lyric works of vocal music lies in the composer's choice to compose the elegance of poetry, which in the future will also affect the composer's choice of the source of other genre literature. Both ancient oriental poetry and modern literary works have inspired the composers.

One of the stylistic features of Chinese composers' vocal works is the basis of recitation, the language required by melody. These folk songs and dramatic genres, such as Hebei Clapper, Henan Clapper and Shanxi Clapper, affect the formation of the melodic language from the theme to the clapper and the presentation way of vocal music. In the development of themes, polyphonic patterns and musical materials, the ups and downs of melody lines play a special role. The rhythmic organization characteristics of some vocal music works are based on the Chinese poetry and premised by the relationship between poetry and poetic style.

One of the most important problems in vocal lyric works is still the relationship between words and music. One is that the poetic rhythm determines the melodic development and rhythm of the theme, and the other is that the author uses the "reverse beat" to look for the processing method of original intonation, which often takes singing tune in the reread and the non-reread syllables as premise.

The national uniqueness of Chinese tradition is shown in different ways in vocal music works. The unique structure full of emotion and undemonstrative emotional expression determine the acceptability of the creation of Chinese composers' vocal works. Most of vocal music works are lyrical. In the creation of vocal music, chords, bass, and repeat tone are used to differentiate sound level through the interval of several seconds, which can be regarded as a principle of the transformation of sound development, and the principle is very characteristic for the representation of the unequal law. The beginning with color is first. Such harmony language has laid the lyric tone for music, and has increased the expression form for creating emotions. Because many works in recent years have used high and low levels of chords, the vivid contrast and image diversity of image - intonation are reproduced.

The expression of many vocal works preserves the folk creation tradition of instrumental accompaniment, and many works essentially has accompaniment color processing, especially giving a romantic image. The elements containing intuitive images continue the tradition of folk instrumental music, and these traditions are also encountered in songs. Often vocal music score and instrumental score are independently developed, and accompaniment is not only a form, but also a subtext of emotional poetry. The national characteristics of the works are determined by the melody expression that can be used to create spatial effects (jumping on large intervals, comparison of the sound area, and strength of grace note).

From the Twentieth Century to early Twenty-first Century, Chinese composers' art songs played a leading role in the development of Chinese professional music art and various folk music compositions. It determines the main features of the vocal music genre and the new trend in the process of its development. In addition, these vocal works also occupy a stable position in the performance repertoire. 


\section{REFERENCES}

[1] Na Ge Gunuer. Vocal Music Teaching in China: the Influence Approaches of China and European Countries/ Na Ge Gunuer, Li Eryun / / Culture \& Science. Works: complete works of academic articles / Belarus National Culture University of the Arts [etc.] - Minsk, 2013, Page $214 \sim 218$ (classification and development trend of vocal art). 娜. 格.加努尔, 中国的声乐教学: 本国与欧洲的影响途径/娜. 格.加 努尔,李尔云//文化，科学。著作：学术文章全集/白俄罗斯国立文 化艺术大学[等等]-明斯克, 2013,214 页-218 页（声乐艺术的分类和 发展趋势）。

[2] Lei Feng. Formation and Development of Chinese Chamber Music, (from 1920s to 1940s), Author Digest... Candidate Doctor, Art Theorist, 17.00.02- music art / Lei Feng - Minsk, 2009, Page 22. 雷锋, 中国室内 乐的形成和发展, (20 世纪 20-40 年代), 作者文摘...副博士, 艺 术理论家,17.00.02-音乐艺术/雷锋-明斯克，2009,22 页。

[3] Jin Qiao. Xiao Youmei and Modern Chinese Music Education. / Jin Qiao, Shanghai: Shanghai Conservatory of Music, 2003 (Doctoral Dissertation) - Page 183. 金桥. 萧友梅与中国近代音乐教育./金桥-上 海: 上海音乐学院, 2003（博士学位论文）-183页。

[4] Chiang Ching. Chinese Music / Chiang Ching, Guan Jianhua, Qian Rong. Beijing: Peking University, 2001, Page 25. 蒋菁.中国音乐大观/ 蒋菁, 管建华, 钱蓉-北京: 北京大学, 2001, -25 页。

[5] Zhao Xiaosheng, Tong Xiang. Music/ Zhao Xiaosheng. Shanghai: Shanghai Music Publishing House, 2006, Page 342. 赵晓生, 同向音乐 圣殿/赵晓生。一上海: 上海音乐出版社, 2006, -342 页

[6] Shi Yingzhao, Classical Music Notes / Shi Yingzhao - Chengdu: Sichuan Literature and Art, 2001, Page 307. 石映照, 古典音乐笔记/ 石映照一程度：四川文艺，2001-307 页。 